\title{
Health protection and sustainable development
}

\author{
Time for joined up thinking
}

$\mathrm{T}$ The effects of environmental exposures on health have recently been addressed by two government documents: one from the Health Protection Agency (HPA) and one, on sustainable development, from the Department for Environment, Food and Rural Affairs (DEFRA). ${ }^{12}$ Although both address specific issues, they seem to have been written without reference to each other, leaving gaps in coverage and a failure to appreciate the need for a wider view of the environment and its impact on health.

The Health Protection Agency, set up in the wake of the New York terrorist attack, embraces the activities previously covered by the Public Health Laboratory Service, the National Radiological Protection Board, the Communicable Disease Surveillance Centre, the National Poisons Information Service, and the regional chemical hazard management groups. The plan defines 12 very broad strategic and laudable goals with which one cannot really argue (box 1).

Importantly, the plan also appreciates the need to extend the work of the agency to chronic exposures to chemicals, accepts the need for horizon scanning on the consequences of exposures to the full range of chemicals released into the environment, and the need to develop staff with the required skills. On this basis one might be forgiven for thinking that this document

\section{Box 1: Health Protection Agency-strategic goals}

To prevent and reduce impact and consequences of infectious diseases

To anticipate and prevent the adverse health effects of acute and chronic exposure to hazardous chemicals and other poisons

To reduce the adverse effects of exposure to ionising and non-ionising radiation

To identify, prepare, and respond to new and emerging diseases and health threats

To identify and develop appropriate responses to childhood diseases associated with infections, chemical or radiation hazards

To improve preparedness of responses to health protection emergencies, including those caused by deliberate release

To strengthen information and communication systems for identifying and tracking diseases and exposures to infectious, chemical, and radiological hazards

To build and improve the evidence base through a comprehensive programme of research

To develop a skilled and motivated workforce

To manage knowledge and share expertise and strengthen international working

To build on and develop the intellectual assets of the organisation in partnership with industry and other customers

To raise the understanding of health protection and the involvement of the public so that there is access to authoritative, impartial, and timely information and advice

\begin{tabular}{|l|}
\hline Box 2: Headline indicators of sustainable \\
development \\
Economic \\
Economic output \\
Investment \\
Employment \\
Social \\
Poverty and social exclusion \\
Education \\
Health \\
Housing \\
Crime \\
Environmental \\
Climate change \\
Air quality \\
Road traffic \\
River water quality \\
Wildlife \\
Land use \\
Waste \\
\hline
\end{tabular}

could be regarded as the United Kingdom's response to the European Union's call for more Europe wide collaborative coherence on the effects of environmental exposures on health, ${ }^{3}$ a call that required each member country to produce a national environmental health action plan. In fact, DEFRA's document on sustainable development was intended as the response to this European call. ${ }^{2}$ It provides a range of 15 headline indicators including one marked "health," embracing life expectancy, air quality, heart disease, and osteoporosis-a rather eclectic collection (box 2).

Some environmental areas remain outside the Health Protection Agency's remit. Responsibility for indoor and outdoor air quality stays in the Department of Health (to whom the Committee on Medical Effects of Air Pollution, COMEAP, acts as an advisory committee) and in the Department for Environment, Food and Rural Affairs (where the Expert Panel on Air Quality Standards, EPAQS, is the advisory committee). Responsibility for the effects of water quality on health remains within the Environment Agency and the Department for Environment, Food and Rural Affairs with some involvement from the Department of Health. ${ }^{4}$ Yet the Health Protection Agency's plan includes responsibility for the health effects of contaminated land (and consequently leachate-run-off water) and from chimney plumes. There is also no clear linkage to the role of the Environment Agency, which overlaps in its remit with some of the Health Protection Agency's strategic roles but which is developing generic health impact assessments for industrial processes. ${ }^{4}$ In particular through integrated pollution prevention and control the Environment Agency aims to help deliver the United Kingdom's Air Quality Strategy.

To understand environmental exposures and their effects, accurate assessment of exposures is crucial in ensuring that the cause and effect framework is identified and dose-response relations quantified. ${ }^{2}$ 
Assessment of acute exposures is often straightforward, but in the chronic setting assessment is often far from easy, although recent developments in assessment of life-long exposure will prove a major advance in improving the estimation of exposure and consequently of dose. ${ }^{5}$ At the other end of the "exposure, effect, control" paradigm, health impact assessment is the linchpin around which establishment of control measures should occur. ${ }^{6}$ Yet, although this is to some extent addressed by the Environment Agency, no mention of Health Impact Assessment is made in either the Health Protection Agency's document or that on sustainable development. Knowledge of all factors contributing to the links between exposures, their effects, and their control does demand coherent collaboration between a range of agencies and skills, ${ }^{2}$ stretching much wider than clinicians, public health doctors, and toxicologists. For instance, advances made in the understanding of the effects of air pollution have been dependent on collaboration between meteorologists, statistical modellers, exposure assessors, physiologists, epidemiologists, clinicians, laboratory scientists, atmospheric chemists, and material physicists in addition to direct input from the public. This multiskilled, crossdisciplinary approach largely emanates from the field of occupational medicine and health.

The Health Protection Agency is only part of the way there. It now needs to think outside the conventional, public health driven box. Its plan rightly talks of the need to train a workforce with the appropriate skills, which need to be broad and embrace other areas of environmental science (for example, hydrology, plant and soil science, and atmospheric chemistry). There is a need to develop integrated ways to train, help establish career paths, and define and undertake the research agenda, embracing the multidisciplinary approach alluded to above. This could be paralleled at a managerial level by considering the merger of COMEAP and EPAQS as an integrated committee dealing with air quality and health issues, and doing so within the Health Protection Agency rather than linked to a specific government department. A similar approach could be taken for the available expertise in the effects of water borne exposures but both these moves would need to consider how best the Health Protection Agency can work with the Environment Agency in this regard.

The thinking which went into these documents should now be joined up and a fresh review across a wider stage be established to ensure a truly integrated plan for delivery of public health protection.

\section{Jon G Ayres professor}

Department of Environmental and Occupational Medicine, University of Aberdeen, Aberdeen AB25 2ZP (j.g.ayres@abdn.ac.uk)

\section{Raymond Agius professor}

Centre for Occupational and Environmental Health, University of Manchester, Manchester M13 9PL (raymond.agius@man.ac.uk)

Competing interests: JA has been chairman of COMEAP since 2001 and a member since 1991. He has been a member of EPAOS since 1996. RA was a member of EPAOS from 1992 to 1995. The views expressed represent the authors' own opinions and are not a reflection of any body to which they belong or have belonged.

1 Health Protection Agency. Corporate plan. 2003-2008. London: HPA 2003. www.hpa.org.uk/hpa/publications/corporateplan2003 8.pd (accessed 16 Jan 2003).

2 Department for Environment, Food and Rural Affairs. Achieving a better quality of life. Review of progress towards sustainable development. London: DEFRA, 2003.

3 Commission of the European Communities. A European environment and health strategy. Brussels, 11 June 2003. (COM (2003) 338. Pub EC health strateg.

4 Environment Agency. Corporate plan 2003-2006. www.environmentEnvironment Agency. Corporate plan 2003-2006. Www.enviro
agency.gov.uk/aboutus/286233/353470/?version=1\&lang=_e (accessed 28 Jan 2003).

5 Cherrie JW, Schneider T. Validation of a new method for structured subjective assessment of past concentrations. Ann Occup Hyg 1999;43:235-49. British Medical Association. Health and environmental impact assessment. An integrated approach. London: Earthscan, 1998.

\title{
Early intervention for first episode psychosis
}

\author{
Needs greater involvement of primary care professionals for its success
}

$\mathrm{E}$ arly intervention in psychosis is a relatively new concept in mental health. It describes the policy of the health service and its response to increasing evidence of unacceptably long delays in accessing specialist services and the benefits of earlier detection and treatment for young people who experience their first episode of psychosis (when someone displays typical symptoms, such as distorted contacts with reality, delusions, hallucinations, and thought disorder, and no organic disorder can be found to explain those symptoms). It is also a concept that requires primary and secondary care and wider involvement of the community to make a difference to the outcome.

Like most mental disorders, functional psychoses such as schizophrenia and bipolar affective disorder usually appear when people are young $(80 \%$ of first episodes of psychoses occur between 16 and 30 years of age), at a critical time in their intellectual and social
Worldwide, the burden of psychosis is exceeded only by quadriplegia and dementia. ${ }^{1}$ The all cause standardised mortality ratio for schizophrenia is 298, with an unnatural cause standardised mortality ratio (that includes suicide) of 1273, 12 times higher than expected. ${ }^{2}$

Studies consistently show intervals of one to two years between the onset of psychotic symptoms and the start of treatment. ${ }^{3}$ Although still disputed, the duration of untreated psychosis is also likely to relate to outcomes in first episode psychosis, particularly functional and symptomatic outcomes at 12 months and reduction of symptoms once treatment begins. ${ }^{45}$ Long term follow up studies show that outcomes at two years strongly predict outcomes 15 years later. Birchwood argues that these observations support the concept that the early phase of psychosis constitutes a critical period for treating this illness, with major implications for secondary prevention of impairments 